${ }^{1}$ Clínica Universidad de los Andes. Santiago, Chile.

anterno Medicina Universidad de los Andes. Santiago, Chile.

Trabajo no recibió financiamiento. Los autores declaran no tener conflictos de interés.

Recibido el 11 de junio de 2018, aceptado el 23 de agosto de

Correspondencia a: Manuel Barrera Oñate Av. Apoquindo 6797 Dpto. 508 Torre 4. Santiago, Chile. mvbarrera@miuandes.cl

\section{Lesiones destructivas de la línea media facial secundarias al consumo de cocaína. Caso clínico}

\author{
MANUEL BARRERA O. ${ }^{a}$, MATÍAS DE LA RIVERA V. ${ }^{a}$, JAVIER VELA U. $^{\mathrm{a}}$, \\ RODRIGO BARRERA M. ${ }^{a}$, GUSTAVO MÖNCKEBERG F. ${ }^{1}$
}

\section{Cocaine induced midline destructive lesions. Report of one case}

Vasculitic midline destructive lesions can be a complication of cocaine use. We report a 44-year-old man who presented with a two months history of left facial pain associated with ipsilateral facial paralysis and a cheek phlegmon. Magnetic resonance imaging showed broad soft tissue destruction linked to important cranial nerve involvement. Antibiotic and antifungal therapy was started and multiple surgical debridement procedures were performed, with no clinical improvement. Microbiological analysis was negative. Finally, thanks to the histologic findings corresponding to vasculitis and granuloma formation and the history of cocaine abuse, a cocaine induced midline destructive lesion was diagnosed.

(Rev Med Chile 2018; 146: 1070-1073)

Key words: Autoimmune Diseases; Cocaine-Related Disorders; Paranasal Sinus Diseases.

\section{E} n Chile, el consumo de cocaína llega a 1,3\% de la población, siendo más frecuente en los estratos socioeconómicos más bajos ${ }^{1}$. En su elaboración se usa con frecuencia el levamisol, un antihelmíntico de uso veterinario conocido por producir cuadros de vasculitis en humanos ${ }^{2}$, dentro de los cuales destaca la lesión destructiva de la línea media facial inducida por cocaína (CIMDL, por sus siglas en inglés).

La CIMDL representa una de las principales formas de presentación de pseudovasculitis inducidas por cocaína ${ }^{3}$, se caracteriza por la destrucción de estructuras óseas y cartilaginosas nasales y sinusales. El daño observado es multifactorial; a nivel local la cocaína provoca vasoconstricción capilar con isquemia secundaria, destrucción mecánica e infecciones secundarias, que contribuyen a perpetuar el daño y a la progresión de este ${ }^{4}$.

Clínicamente, se puede manifestar como obstrucción nasal crónica, epistaxis y dolor facial severo, apareciendo disfagia y reflujo nasal al comprometerse el paladar ${ }^{5}$. En la evaluación inicial, la resonancia nuclear magnética (RNM) permite objetivar de mejor manera el compromiso estructural, observando erosiones de tejidos blandos, perforación del paladar blando, destrucción de cornetes nasales o edema de tonsilas palatinas y faríngeas ${ }^{6}$. El diagnóstico diferencial más importante es la granulomatosis con poliangeitis (GPA). Las claves que podrían orientar a una CIMDL son el compromiso extenso de estructuras faciales y la presencia de anticuerpos anticitoplasma de neutrófilos, especialmente con patrón perinuclear (ANCA-p), con especificidad para antígenos como la elastasa de neutrófilos humana $(\mathrm{HNE})^{7}$. Ambas patologías comparten hallazgos histopatológicos similares, siendo la presencia de granulomas más característica de la GPA, sin embargo, puede verse ocasionalmente en pacientes con $\mathrm{CIMDL}^{5}$.

El presente artículo tiene como objetivo presentar un caso de CIMDL, en el que después de 
un amplio ejercicio de diagnóstico diferencial, finalmente se llega al diagnóstico a través del interrogatorio dirigido, repetido y persistente, enfocado en la existencia de consumo y abuso de cocaína que el paciente había negado.

\section{Caso clínico}

Hombre de 44 años, con antecedentes de diabetes mellitus tipo 2 mal controlada, derivado a nuestro centro por un cuadro de 2 meses de evolución caracterizado por dolor facial izquierdo intenso y refractario. Se trató inicialmente como periodontitis, con extracción de molar superior izquierdo y antibioticoterapia oral. Evolucionó tórpidamente, con parálisis facial izquierda, dolor intenso, edema y epistaxis, por lo que se realizó una tomografía axial computada (TAC) de macizo facial, la que demostró pansinusitis, asociado a compromiso inflamatorio periorbitario izquierdo.

Se hospitalizó para completar estudio con RNM, mostrando extenso compromiso inflamatorio de partes blandas superficiales y profundas craneofaciales izquierdas, con extensión a través de las ramas del trigémino, colección de fosa media, neuritis del VII par, sinusitis etmoidomaxilar y proceso inflamatorio petromastoideo izquierdo (Figura 1). Se realizó aseo quirúrgico y se inició terapia antibiótica endovenosa con ceftriaxona y clindamicina por 10 días. La RNM de control evidenció progresión del proceso inflamatorio.

Se realizó nuevo aseo encontrándose tejido necrótico y secreción purulenta a nivel maxilar. Se tomó biopsia rápida que informó tejido necrótico y presencia de granulomas, además de estudio microbiológico completo para bacterias, hongos y mycobacterias. Se sospechó mucormicosis y se inició anfotericina B liposomal $5 \mathrm{mg} / \mathrm{kg}$ al día, asociado a vancomicina $1 \mathrm{~g} \mathrm{c} / 8 \mathrm{~h}$ e imipenem $500 \mathrm{mg}$ cada 6 h endovenosos, completando 7 días de terapia antibiótica.

Se informaron cultivos negativos (corriente, para hongos y bacilo de Koch), reacción en cadena de polimerasa (PCR) universal y de hongos negativos, VIH negativo, galactomanano y beta-D-glucano negativos. Se realizó tercer aseo quirúrgico y se tomaron nuevas biopsias, evidenciando proceso inflamatorio crónico activo granulomatoso, no se encontraron hifas. El hemograma mostró indem- nidad de las tres series y tanto la histología como el estudio inmunohistoquímico fueron negativos para la presencia de linfoma nasal de células $\mathrm{T} /$ NK. Tampoco la histología fue consistente con la presencia de sarcoidosis y tanto los niveles de enzima convertidora de angiotensina (ECA) como vitamina $\mathrm{D}$ fueron normales.

Ante la sospecha de GPA, se inició terapia con metilprednisolona $250 \mathrm{mg}$ al día endovenoso durante 3 días y luego prednisona oral $1 \mathrm{mg} / \mathrm{kg} /$ día. La TAC de tórax descartó la presencia de nódulos y cavitaciones pulmonares. El estudio inmunológico resulta negativo para ANCA por IFI y ELISA (PR3 y MPO). Tampoco se demostró presencia de vasculitis en otros órganos; función renal normal con sedimento de orina no inflamatorio, ausencia de lesiones cutáneas y a nivel de sistema nervioso periférico.

Si bien el paciente había negado en múltiples ocasiones el consumo de drogas, se insistió en la indagación previo al inicio de ciclofosfamida, explicándole los riesgos de la terapia, razón por la que confesó abuso de cocaína y poliadicción. Con diagnóstico de CIMDL, se planificó rápida reducción de la dosis de prednisona y se solicitó apoyo al equipo de Psiquiatría.

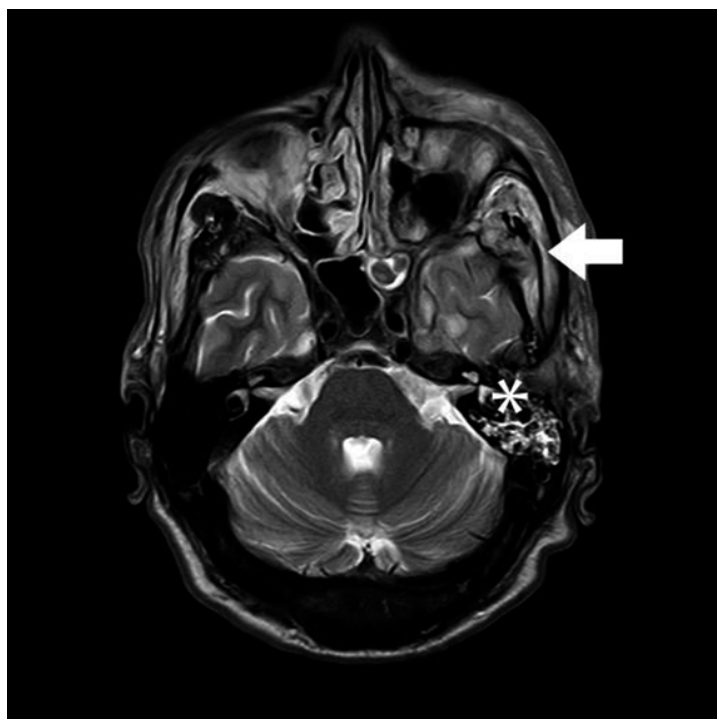

Figura 1. Resonancia magnética cerebro y órbitas con contraste que muestra extenso compromiso inflamatorio de partes blandas superficiales y profundas craneofaciales izquierdas (flecha). Proceso inflamatorio petromastoideo izquierdo (asterisco). 


\section{Discusión}

La patogénesis de la CIMDL no está aclarada completamente, se sospecha que estarían implicados mecanismos inflamatorios, infecciosos, proapoptóticos y autoinmunes. La magnitud de destrucción de la mucosa nasal, el tiempo y la dosis de cocaína utilizada podrían ser factores de riesgo para desarrollar el cuadro ${ }^{7}$.

La mayoría de estos pacientes suelen negar el consumo, por lo que se hace fundamental la interrogación reiterativa.

Dentro del examen físico, los hallazgos característicos son úlceras necrotizantes, lesiones costrosas y perforación septal, en casos graves la destrucción se puede extender hacia los cornetes nasales o la pared lateral. Algunos pacientes pueden presentar lesiones palatinas ocasionando disfagia y reflujo nasal, mientras que en etapas avanzadas pueden desarrollar síntomas producto de la propagación de las infecciones como proptosis y diplopía. Los síntomas sistémicos como fiebre, malestar, pérdida de peso, artralgias o mialgias suelen estar ausentes ${ }^{6}$.

La sospecha clínica es en base a las características clínicas, imagenológicas y de laboratorio, buscando diferenciarlo principalmente de la GPA. Una manera de orientarse es mediante la evaluación de la distribución de las lesiones, las cuales presentan una destrucción local mayor y más centrífuga en el caso de la CIMDL en comparación a las lesiones de los pacientes con GPA, siendo, además, poco frecuente las manifestaciones exclusivamente nasales. En cuanto al estudio imagenológico, la TAC aporta escasa información, mostrando en casos graves una progresión centrífuga del daño óseo y cartilaginoso. La RNM, por su parte, permite objetivar mejor el compromiso estructural y la extensión local de las lesiones. Algunas de las características radiológicas incluyen áreas hipodensas en T2 como resultado de alteraciones en la mucosa nasal y paranasal, erosiones de tejidos blandos, perforación del paladar blando, destrucción de cornetes nasales o edema de tonsilas palatinas y faríngeas ${ }^{8}$.

La sospecha se confirma mediante el uso de ensayos inmunológicos, específicamente con la presencia de $\mathrm{ANCA}^{7}$, los cuales suelen tener un patrón de inmunofluorescencia perinuclear (ANCA-P) y una especificidad antigénica hacia la elastasa neutrofílica humana (HNE) en el caso del
CIMDL, y un patrón citoplasmático (ANCA-C) con especificidad hacia la proteinasa-3 (PR3) en el caso de la GPA ${ }^{3}$. En nuestro caso, la presencia de un ANCA-P específico para HNE hubiera hecho el diagnóstico de certeza.

Otras causas de lesiones destructivas de la línea media deben ser consideradas (Tabla 1). La mucormicosis se presenta en pacientes inmunocomprometidos con un cuadro clínico que puede ser similar, afectando tanto cavidades nasales, como paranasales e incluso orbitarias. El diagnóstico definitivo es mediante confirmación microbiológica del agente tanto en cultivo como PCR específica9 .

El linfoma nasal de células T/NK o granuloma de la línea media también se caracteriza por ser un proceso inflamatorio granulomatoso y con tendencia a la necrosis. Afecta de la misma manera estructuras nasales, senos paranasales y paladar, teniendo una evolución fatal a corto plazo en la mayoría de los pacientes ${ }^{10}$. La biopsia muestra infiltrado linfoide polimorfo y células tumorales, mientras que la inmunohistoquímica para marcadores CD56, CD2, CD3 o proteínas asociadas a gránulos citotóxicos (PGC) resulta positiva $^{11}$. También se puede plantear la sarcoidosis extrapulmonar con manifestaciones nasales. La histología de este granuloma se caracteriza por ser no necrotizante, mientras que el laboratorio revelará niveles de ECA elevados y vitamina D elevados ${ }^{12}$.

El manejo terapéutico es un desafío, ya que es fundamental el cese del abuso de cocaína, sin embargo, existe poca adherencia a esta medida por parte de los consumidores ${ }^{13}$. Si bien la enfermedad se presenta como una vasculitis, no hay lugar para la terapia inmunosupresora ${ }^{5}$. Sin embargo, son recomendadas las medidas conservadoras locales como desbridamiento cuidadoso del tejido necrótico, lavado con soluciones salinas y uso de antibióticos locales o sistémicos. Respecto de las secuelas físicas ocasionadas como las perforaciones septales y paladares, o fístulas nasocutáneas, el uso de prótesis y la cirugía pueden lograr buenos resultados, pero estas medidas deben quedar supeditadas al cese del hábito, para prevenir la falla del tratamiento. Pese a lo anterior, la duración mínima del período de abstinencia antes de plantear un procedimiento quirúrgico eficaz y seguro es debatido entre los distintos autores, planteándose períodos de entre 6 a 12 meses de abstinencia demostrada ${ }^{5}$. 
Tabla 1. Diagnósticos diferenciales de lesiones destructivas de la línea media facial

\begin{tabular}{|c|c|c|c|c|c|}
\hline Diagnóstico & CIMDL & GPA & Linfoma & Mucormicosis & Sarcoidosis \\
\hline Clínica & $\begin{array}{l}\text { Antecedente de } \\
\text { consumo de co- } \\
\text { caína, dolor facial, } \\
\text { epistaxis, compro- } \\
\text { miso del paladar }\end{array}$ & $\begin{array}{l}\text { Sinusitis, costras } \\
\text { nasales, defor- } \\
\text { midad en silla } \\
\text { de montar, tos, } \\
\text { disnea, hematuria }\end{array}$ & $\begin{array}{l}\text { Obstrucción nasal, } \\
\text { epistaxis, destruc- } \\
\text { ción paranasal o } \\
\text { del paladar }\end{array}$ & $\begin{array}{l}\text { Pacientes inmuno- } \\
\text { comprometidos, } \\
\text { rinorrea purulen- } \\
\text { ta, dolor facial, } \\
\text { necrosis del pala- } \\
\text { dar, compromiso } \\
\text { orbitario }\end{array}$ & $\begin{array}{l}\text { Obstrucción nasal, } \\
\text { costras nasales, } \\
\text { anosmia, epistaxis, } \\
\text { poliposis nasal, } \\
\text { rinitis atrófica }\end{array}$ \\
\hline Laboratorio & $\begin{array}{l}\text { ANCA-p (+) para } \\
\text { antígeno de HNE }\end{array}$ & $\begin{array}{l}\text { ANCA-p }(+) \text { para } \\
\text { MPO } \\
\text { ANCA-c }(+) \text { para } \\
\text { PR3 }\end{array}$ & $\begin{array}{l}\text { Marcadores tumo- } \\
\text { rales. CD2, CD3, } \\
\text { CD56, PGC }\end{array}$ & $\begin{array}{l}\text { Cultivos para hon- } \\
\text { gos }(+) \\
\text { PCR para hongos } \\
(+)\end{array}$ & $\begin{array}{l}\text { Niveles de ECA } \\
\text { elevados } \\
\text { Niveles de vitamina } \\
\text { D elevados }\end{array}$ \\
\hline Imágenes & $\begin{array}{l}\text { Erosiones de tejidos } \\
\text { blandos, cartilagi- } \\
\text { nosos u óseos }\end{array}$ & $\begin{array}{l}\text { Engrosamiento } \\
\text { mucosa nasal y } \\
\text { paranasal, destruc- } \\
\text { ción ósea nasal }\end{array}$ & $\begin{array}{l}\text { Masas de tejido } \\
\text { blando. Remo- } \\
\text { delación ósea y } \\
\text { destrucción lítica } \\
\text { en cavidad nasal y } \\
\text { maxilar }\end{array}$ & $\begin{array}{l}\text { Edema de tejido } \\
\text { blando engrosa- } \\
\text { miento de mucosa } \\
\text { y periostio, erosio- } \\
\text { nes óseas }\end{array}$ & $\begin{array}{l}\text { Hallazgos inespecí- } \\
\text { ficos como masas, } \\
\text { nódulos, cavita- } \\
\text { ciones }\end{array}$ \\
\hline Histología & $\begin{array}{l}\text { Infiltrados infla- } \\
\text { matorios necrosis } \\
\text { fibrinoide, vasculitis } \\
\text { y granulomas oca- } \\
\text { sionales }\end{array}$ & $\begin{array}{l}\text { Infiltrados inflama- } \\
\text { torios granulomas } \\
\text { estromales con } \\
\text { células gigantes, } \\
\text { necrosis profunda }\end{array}$ & $\begin{array}{l}\text { Infiltrado linfoide } \\
\text { polimorfo peri- } \\
\text { vascular, necrosis } \\
\text { fibrinoide. Células } \\
\text { tumorales }\end{array}$ & $\begin{array}{l}\text { Identificación de } \\
\text { organismo con } \\
\text { estructura de hifas } \\
\text { no septadas, infla- } \\
\text { mación neutrofílica } \\
\text { y granulomatosa }\end{array}$ & $\begin{array}{l}\text { Granulomas epite- } \\
\text { lioides no necroti- } \\
\text { zantes }\end{array}$ \\
\hline
\end{tabular}

$\mathrm{CIMDL}=$ Lesiones destructivas de la línea media facial inducidas por cocaína; GPA = Granulomatosis y poliangeitis; HNE = Elastasa de neutrófilos humana; PGC = Proteínas asociadas a gránulos citotóxicos; PCR = Reacción en cadena de polimerasa; $\mathrm{ECA}=$ Enzima convertidora de angiotensina.

\section{Referencias}

1. Servicio Nacional para la Prevención y Rehabilitación del Consumo de Drogas y Alcohol. Décimo primer estudio nacional de drogas en población general; Julio 2015; Disponible en: http://www.senda.gob.cl/wp-content/ uploads/2015/07/Informe-Ejecutivo-ENPG-2014.pdf

2. Berman M, Paran D, Elkayam O. Cocaine-Induced Vasculitis. Rambam Maimonides Med J 2016; (4): 1-5.

3. Wiesner O, Russell KA, Lee AS, Jenne DE, Trimarchi M, Gregorini G, et al. Antineutrophil Cytoplasmic Antibodies Reacting With Human Neutrophil Elastase as a Diagnostic Marker for Cocaine-Induced Midline Destructive Lesions but Not Autoimmune Vasculitis. Arthritis Rheum 2004; 50 (9): 2954-65.

4. Rubin K. The manifestation of cocaine-induced midline destructive lesion in bone tissue and its identification in human skeletal remains. Forensic Sci Int 2013; 231 (1-3): 408.e1-408.e11.

5. Trimarchi M, Bussi M, Sinico RA, Meroni P, Specks U. Autoimmunity Reviews Cocaine-induced midline destructive lesions-An autoimmune disease? Autoimmun Rev 2013; 12 (4): 496-500.
6. Morassi ML, Trimarchi M, Nicolai P, Gregorini G, Maroldi R, Specks U, et al. [Cocaine, ANCA, and Wegener's granulomatosis]. Pathologica 2001; 93 (5): 581-3.

7. Graf J. Rheumatic manifestations of cocaine use. Curr Opin Rheumatol 2013; 25 (1): 50-5.

8. Trimarchi M, Bertazzoni G, Bussi M. Cocaine induced midline destructive lesions. Rhinology 2014; 52 (2): 104-11.

9. DelGaudio JM, Swain RE, Kingdom TT, Muller S, Hudgins PA. Computed tomographic findings in patients with invasive fungal sinusitis. Arch Otolaryngol Head Neck Surg 2003; 129 (2): 236-40.

10. Lorely D, Marquez E, Fuste JRC. Granuloma letal de la línea media como diagnóstico diferencial de la vasculitis de Wegener. Presentación de una paciente. Acta Médica del Cent 2015; 9 (2): 34-40.

11. Koeller KK. Radiologic Features of Sinonasal Tumors. Head Neck Pathol 2016; 10 (1): 1-12.

12. M. Iannuzzi, B. Rybicki, A. Teirstein. Sarcoidosis. N Engl J Med 2007; (357): 2153-65.

13. Trimarchi M, Nicolai P, Lombardi D, Facchetti F, Morassi ML, Maroldi R, et al. Sinonasal osteocartilaginous necrosis in cocaine abusers: experience in 25 patients. Am J Rhinol 2003; 17 (1): 33-43. 